\title{
O sítio de tradição Aratu de Água Vermelha, Reserva Indígena Caramuru Paraguaçu, e suas implicações arqueológicas e etno-políticas.
}

\author{
Carlos Etchevarne \\ Universidade Federal da Bahia (UFBA)
}

\begin{abstract}
O achado circunstancial de urnas funerárias na localidade de Agua Vermelha na Reserva Indigena Caramuru Paraguassu, por membros das comunidades étnicas ali instaladas, coloca em discussão dois aspectos sócio-históricos. O primeiro refere-se às populações pré-coloniais, associadas arqueologicamente a uma macro unidade denominada Tradição Aratu, cujo elemento diacrítico principal são as urnas funerárias, como as encontradas na reserva. Por outro lado, a situação particular pela que passam hoje as comunidades, em termos de definição de limites territoriais, faz com que esses objetos sejam ressignificados e lhe sejam atribuidos um papel documental, como marcos concretos sobre a presença indigena na região, ainda que não sejam vinculados, diretamente, à ocupação contemporânea.

Palavras-Chave: urnas funerárias, arqueologia baiana, indígenas da Bahia, cerâmica arqueológica
\end{abstract}

a localidade de Água Vermelha, dentro da Reserva Indígena Caramuru Paraguaçu,
município de Pau Brasil, a descoberta de urnas funerárias não pode ser considerada como de data recente. A retirada de três recipientes funerários por parte de uma equipe da UFBA, em fevereiro de 2011, significou apenas a identificação oficial para a pesquisa acadêmica e para os órgãos de proteção do patrimônio cultural, de uma situação vestigial, que já era conhecida por muitos membros dos quatro grupos étnicos que compõem a reserva. Quando convocados pelos agentes do Conselho Indigenista Missionário, em Itabuna, solicitados, por sua vez, pelo cacique Gerson Souza Melo, os pesquisadores souberam que nas imediações do local do achado e em algumas outras áreas das redondezas já tinham sido reconhecidos vasilhames funerários do tipo que fora motivo da visita técnica. Ou seja, foram surpreendidos pela quantidade de material existente na área próxima às urnas e pelo potencial que a região oferece, no que se refere a localidades arqueológicas vinculadas a assentamentos indígenas pré-coloniais, ou seja, de antigas aldeias.

Água Vermelha é um grande sítio arqueológico relacionado a um grupo indígena pré- 
colonial englobado, convencionalmente, em uma macro unidade cultural, denominada Tradição Aratu. Cabe ressaltar que com o termo "tradição" os arqueólogos brasileiros designam sítios e conjuntos de materiais arqueológicos considerados diagnósticos que se repetem, com bastante freqüência, ao longo de um período e se distribuem em um amplo território. Trata-se, a fortiori, de um artifício metodológico para tentar identificar, classificar e compreender com um bom grau de coerência o vasto universo de vestígios materiais de diferentes grupos sociais que perduraram até hoje. Não obstante, é necessário apontar o risco que se corre na aplicação destas categorias classificatórias nos estudos arqueológicos de sítios pré-coloniais, posto que nem sempre elas estão determinando limites étnicos precisos. Pelo contrário, cabe pensar, que sob denominação de Tradição, definidas apenas por alguns aspectos fragmentários da cultura material, podem ficar mascaradas diversas situações sociais, entre elas as identintárias, de difícil, quando não impossível, reconhecimento atual. O próprio nome Aratu, por exemplo, faz referência apenas à primeira localidade onde foi encontrado esse tipo de material arqueológico e não ao nome do um grupo social, tendo em vista que não havia documentos escritos nem tradição oral que os permitisse identificar.

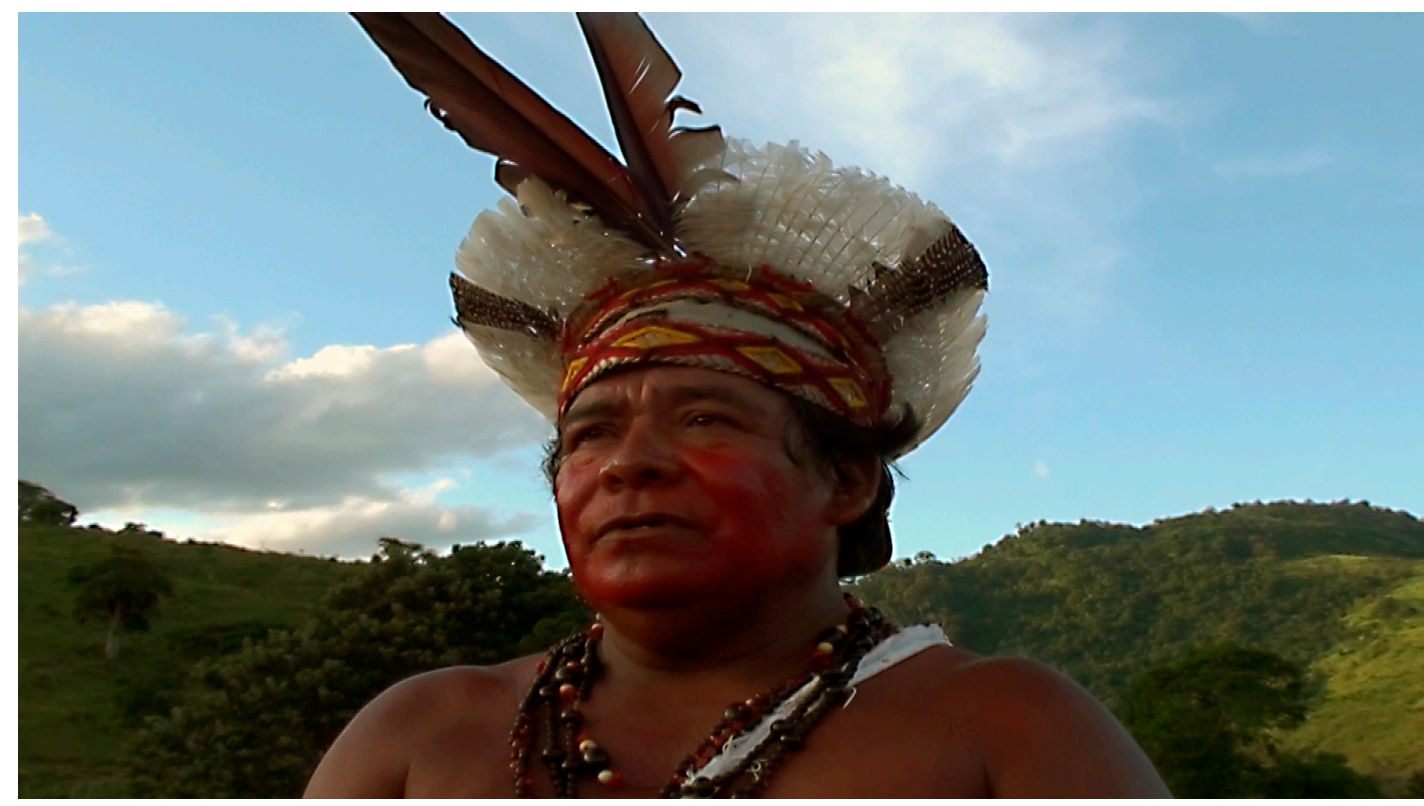

“Urnas funerárias indígenas em terras Pataxó Hã-Hã-Hãe”. Direção: Bainan, Fábio Titiá e Yonana. Brasil 2011.

No que se refere ao Nordeste brasileiro existem duas grandes unidades culturais pré-coloniais, ou tradições arqueológicas, que foram denominadas Aratu e Tupi. Ambas estão associadas a grupos sociais demograficamente numerosos, isto é de grandes aldeias, com conhecimento de cultivos de algumas espécies como parte essencial da dieta alimentar e, ainda, produtores de cerâmica com múltiplas funções e com aspectos tecnológicos adequados à utilização doméstica ou ritualística. Em nenhum dos dois casos faziam uso de metais e os instrumentos para o tratamento dos vegetais e animais eram, em grande parte, em pedra lascada ou polida.

Em termos cronológicos os grupos da Tradição Aratu são os primeiros a se instalarem em território do Nordeste, conforme as datações de C 14 e de TL (termoluminescência) conseguidas até o momento, que os insere em uma faixa temporal que abarca um lapso entre 1200 anos BP e 600 anos BP aproximadamente (isto é, do século IX ao século XV d.C.). Já 
os dados arqueológicos revelam que as ocupações dos primeiros grupos Tupi correspondem a uma idade de 1.100 anos BP (século X) e que se estendem até o período de contato com os portugueses, no século XVI, época em que já dominavam grande parte do litoral nordestino, conforme pode ser identificado pelas várias descrições de cronistas europeus.

Os grupos de Tradição Aratu podem ser encontrados em ambientes ecológicos diferentes como o cerrado e a mata atlântica, com as correspondentes variações topográficas, hídricas e litológicas. Até o momento não houve registros arqueológicos que comprovem que esses grupos tenham ocupado as grandes regiões interioranas da caatinga nordestina. Esta é, sem dúvida, uma linha de pesquisa que deverá ser seguida, porque essa ausência pode estar indicando que os grupos Aratu não souberam criar ajustes adaptativos às condições do semi-árido, circunscrevendo-se apenas às regiões com bom índice e regularidade de pluviosidade, que garantiriam os cultivos necessários para o abastecimento alimentar de um grande grupo e permitiriam a sua estabilidade em um local.

Os elementos materiais diacríticos da Tradição Aratu são, sem lugar a dúvidas, as urnas funerárias. A forma de deposição dos indivíduos mortos, integrantes do grupo, em urnas parece ter sido fortemente predominante, havendo enterramentos de idosos, adultos, jovens, adolescentes, crianças e até de recém nascidos. Todos eles foram colocados em recipientes cerâmicos com a mesma morfologia, variando, unicamente, de tamanho conforme a idade do indivíduo a ser enterrado. As urnas eram piriformes (formato de pêra ou jambo invertido), fechadas, a maioria das vezes, por um opérculo coniforme. O corpo era colocado de forma completa, classificandose como enterramento primário. Isto pressupõe uma colocação do indivíduo anterior à rigidez cadavérica, que impediria a flexão dos membros (pernas e braços), para deixar o corpo em posição fetal. Até onde foi possível em todas as urnas o posicionamento do corpo era o mesmo.

Convêm particularizar as urnas funerárias como artefato, posto que as variações morfológicas ou decorativas podem apontar alguns aspectos de caráter sócio-histórico locais ou regionais. Elas apresentam sempre um tratamento de superfície alisado e bordas simples. Em alguns casos colocaram uma incisão em torno da abertura (como em São Desidério, oeste baiano) ou uma faixa corrugada, também circundando a boca, como acontece em Água Vermelha e na maior parte dos sítios Aratu do litoral sul do estado da Bahia. Esta faixa corrugada espatulada, com forma de telhado ou de "casco de tatu", como foi identificada por alguns membros da comunidade de Água Vermelha, não é o tradicional resultado do tratamento dos próprios roletes de confecção do vasilhame, mas da aplicação de outros, sobre a superfície, em que foram pressionados para formar as ondulações rítmicas, características desta decoração. Os opérculos que acompanham as urnas também são de forma bastante padronizada, complementando-se nesse sentido, com o receptáculo funerário. Pode-se afirmar que, salvo esses elementos distintivos, as urnas, assim como o conteúdo delas, formam um padrão de sepultamento muito estável ao longo do tempo e do território da Bahia. Nos sítios, as urnas distribuem-se agrupadas ou isoladas, sempre fora das manchas escuras do solo, identificadas com resultado da decomposição das palhoças.

Por outro lado, os fragmentos de recipientes cerâmicos encontrados em superfície, isto é, que não foram propositalmente enterrados como as urnas, podem ser considerados restos dos equipamentos utilizados em tarefas domésticas de processamento e serviço de alimentos, ainda que muitos deles, eventualmente, possam ter servido também para fins ritualísticos. São partes de vasilhames que tinham formas simples, semiesféricas ou conoidais, com boa cocção, paredes bem alisadas e muitas delas, como no caso de Água Vermelha, com um tratamento à 
base de grafite. De fato, neste caso, um alto percentual de fragmentos apresentava, sobretudo na parte interna, uma fina película de grafite que, aparentemente, foi aplicada por fricção, depois da queima. O grafitado pode ser explicado como um recurso visual, que poderia chegar a ter outras conotações, como as ritualísticas, por exemplo, mas também pela sua funcionalidade, já que ele permite uma maior vedação da porosidade da matéria cerâmica. Os opérculos das urnas também foram revestidos internamente com grafite. Além deste tratamento de superfície, seja em Água Vermelha como no litoral sul da Bahia, houve a aplicação de algumas técnicas decorativas como o corrugado em faixas (simples ou espatulado), o roletado ou acordelado, ungulado e inciso com vários motivos.

Na década de 70 do século XX, o arqueólogo Valentin Calderón, da UFBA, identificou esta variação da Tradição Aratu e a registrou pela primeira vez no município de Itanhém, no sul do estado da Bahia. Em Água Vermelha, a vinculação de material corrugado e grafitado com a modalidade simples da Tradição Aratu está constatada, de maneira irrefutável, pelo achado de uma das 3 urnas coletadas, completamente lisa, do tipo como é encontrada no litoral centro e norte da Bahia e no além São Francisco.

O fato de existirem aspectos decorativos sobre parte das superfícies alisadas das urnas pode estar indicando alguma interação com grupos não Aratu, que atingem um elemento fortemente convencional e conservador como as urnas funerárias. As datações realizadas sobre material de Água Vermelha e sobre uma urna do Quadrado de Trancoso, com as mesmas características, se equivalem, posto que ambas se enquadram na primeira metade do século XIV (cerca de 670 anos e 650 anos BP respectivamente). Outros sítios arqueológicos com material cerâmico semelhante foram encontrados em Eunápolis, próximos a Porto Seguro. Essas duas datações representam um momento particular em que grupos pertencentes a um horizonte cultural bastante homogêneo, do ponto de vista da cultura material, ocupavam um amplo território no litoral sul baiano.

As datações mencionadas colocam os sítios arqueológicos no cenário de um panorama sócio-histórico regional em que sobressai a forte penetração dos grupos Tupi, que podem ter influenciado outros grupos, em um processo de incorporação de populações ou de dominação política. Esta força expansionística acabaria impondo certos aspectos do modus vivendi dos grupos Tupi, como em qualquer situação de contato assimétrico, envolvendo também alguns detalhes das técnicas de produção cerâmica. Neste sentido, cabe lembrar que a técnica de corrugado é muito característica dos recipientes Tupi, especialmente os esféricos. As faixas corrugadas nas urnas Aratu poderiam ter sua origem em uma situação deste tipo, ou seja, estariam mostrando apenas um detalhe de uma dinâmica de transformação em que certos grupos Aratu adotam, pela pressão de contato, elementos próprios de outra sociedade, neste caso a dos Tupi.

O outro aspecto relevante que apresenta o sítio de Água Vermelha é a circunstância específica da sua localização: a Reserva Indígena Caramuru Paraguaçu. Os membros das quatro etnias que ali residem (Kariri Sapuiá, Pataxó Hahãhãe, Kamakã e Tupinambá, Baenã) vêm no material arqueológico de Água Vermelha a possibilidade de ter mais um subsídio para reivindicar essa porção da reserva indígena que foi desmembrada por um processo de outorga de títulos de propriedade a fazendeiros do cacau a partir da década de 70 do século XX. $\mathrm{O}$ processo de restituição da posse dessa área, movido pelos índios, transita no supremo Tribunal de Justiça em Brasília. 
O relatório preparado e entregue ao cacique Gerson Sousa Melo, juntamente com a datação radiocarbônica realizada no laboratório Beta Analytic, de Miami (USA), foi muito bem recebido pelas comunidades indígenas da reserva Caramuru Paraguaçu, porque funcionaria como um laudo técnico por parte de especialistas da UFBA, com uma prova de idade efetuada em uma instituição reconhecida internacionalmente. De fato, ela estabelece uma ocupação anterior à chegada dos portugueses, ao Brasil, e pode legitimar a ocupação atual se bem instrumentada. Por isso, esse relatório foi entregue à procuradora pública encarregada do caso e circula nas instâncias judiciais, como peça do processo.

Cabe ressaltar que em termos de ocupação indígena é muito difícil provar a continuidade étnica em determinada área até pela própria natureza ideológica da construção identitária. A maioria das vezes, a natural dinâmica sócio-histórica que envolve os grupos humanos em um determinado território é reconstruída, arqueologicamente, de forma muito fragmentária e irregular, havendo grandes lapsos de tempo com lacunas informativas. Não obstante, a própria materialidade das provas arqueológicas, como é o caso das cerâmicas, permite estabelecer vínculos culturais com as populações indígenas pré-coloniais, ao tempo que a distancia de outros elementos tradicionais da sociedade envolvente, de origem européia.

Para os membros dos grupos indígenas da reserva Caramuru Paraguaçu, cientes dessas limitações de informações, o que parece importar não é necessariamente a determinação étnica do grupo do qual resulta o sítio arqueológico e da sua continuidade nas comunidades contemporâneas. Ao final, eles mesmos constituem um bom exemplo de uma realidade social complexa, em que em uma mesma área convivem grupos étnicos diferentes que compartilham inúmeros elementos culturais tradicionais, e muitos não tradicionais, em circunstâncias sóciopolíticas que os aproximam de tal forma que os tornam indeferenciados para a sociedade nacional não indígena.

\title{
The Aratu excavation site of Água Vermelha, Caramuru Paraguassu INDIGENOUS RESERVE, AND ITS ARCHAEOLOGICAL AND POLITICAL SIGNIFICANCE
}

\begin{abstract}
The circumstantial discovery of funerary urns at Agua Vermelha on the Caramuru Paraguassu Indigenous Reserve by local ethnic communities begs the discussion of two socio-historical aspects. The first refers to pre-colonial populations archaeologically associated to a macro unit called the Aratu Tradition, whose major diachronic element are funerary urns such as the ones found at the Reserve. On the other hand, the community's current situation, as it relates to the definition of territorial limits, leads to the objects' re-signification and to their use as a document, which serves as concrete evidence of the indigenous presence in the region, even if it's not directly linked to the current occupation.
\end{abstract}

Keywords: funeral urns, Brazilian arqueology, Brazilian Indians, pottery 